\title{
Time Dependence of Tip Morphology During Cellular Dendritic Arrayed Growth
}

\section{Hui Song}

Cleveland State University

Follow this and additional works at: https://engagedscholarship.csuohio.edu/encbe_facpub

jirendra N. Tewari

Uevertand state Gnterialsitycience and Engineering Commons, and the Transport Phenomena Commons

How does access to this work benefit you? Let us know!

\section{Publisher's Statement}

Copyright 1996 ASM International. This paper was published in Metallurgical and Materials Transactions A: Physical Metallurgy and Materials Science, Vol. 27, Issue 4, pp. 1111-1119 and is made available as an electronic reprint with the permission of ASM International. One print or electronic copy may be made for personal use only. Systematic or multiple reproduction, distribution to multiple locations via electronic or other means, duplications of any material in this paper for a fee or for commercial purposes, or modification of the content of this paper are prohibited.

Available on publisher's site at: http://www.springerlink.com/content/qg24346484p93v7n/.

\section{Original Citation}

Song, H., \& Tewari, S.N. (1996). Time Dependence of Tip Morphology During Cellular Dendritic Arrayed Growth. Metallurgical and Materials Transactions A: Physical Metallurgy and Materials Science 27, 1111-1119.

\section{Repository Citation}

Song, Hui and Tewari, Surendra N., "Time Dependence of Tip Morphology During Cellular Dendritic Arrayed Growth" (1996). Chemical \& Biomedical Engineering Faculty Publications. 13.

https://engagedscholarship.csuohio.edu/encbe_facpub/13

This Article is brought to you for free and open access by the Chemical \& Biomedical Engineering Department at EngagedScholarship@CSU. It has been accepted for inclusion in Chemical \& Biomedical Engineering Faculty Publications by an authorized administrator of EngagedScholarship@CSU. For more information, please contact library.es@csuohio.edu. 


\title{
Time Dependence of Tip Morphology during Cellular/Dendritic Arrayed Growth
}

\author{
H. SONG and S.N. TEWARI
}

Succinonitrile-1.9 wt pct acetone has been directionally solidified in $0.7 \times 0.7$-cm-square cross section pyrex ampoules in order to observe the cell/dendrite tip morphologies, not influenced by the "wall effects," which are present during growth in the generally used thin (about $200 \mu \mathrm{m}$ ) crucibles. The tips do not maintain a steady-state shape, as is generally assumed. Instead, they fluctuate within a shape envelope. The extent of fluctuation increases with decreasing growth speed, as the micro structure changes from the dendritic to cellular. The influence of natural convection has been examined by comparing these morphologies with those grown, without convection, in the thin ampoules.

\section{INTRODUCTION}

DIRECTIONAL solidification of alloys in a positive thermal gradient $\left(G_{1}\right)$ at a constant growth speed $(R)$ produces an arrayed morphology of dendrites or cells. The microstructure and chemical homogeneity of directionally solidified materials are significantly affected by the tip morphology of these arrays. Therefore, considerable effort has gone into developing an understanding of the tip shape. Thermal gradient, growth speed, and alloy composition dependence of the tip morphology have been extensively examined in transparent organic alloys, such as succinonitrile-acetone, ${ }^{[1,2,3]}$ pivalic acid-ethanol, ${ }^{[4]}$ and succinonitrile-salol. ${ }^{[5]}$ The experimental observations generally showed that a steady-state tip morphology develops for an alloy growing at constant $G_{1}$ and $R$, for both the cellular and dendritic arrays. Several analytical ${ }^{[6-10]}$ and numerical $^{[1,12,13]}$ analyses have been carried out to explain the steady-state morphology of cells and dendrites. However, there has been little attempt to experimentally examine the time dependence of the tip morphology during constrained growth of binary alloys in order to ascertain if they do keep a steady-state shape. Indeed, recent theoretical analyse S $^{[13,14]}$ suggest that there may not be a sharp selection of primary arm spacings (tip morphology) during dendritic arrayed growth. It is also important to note that the tip morphology data on transparent materials have mostly been generated in thin (about 100 to $200 \mu \mathrm{m}$ ) slab-shaped crucibles. Since the solid succinonitrile is known to preferentially wet the glass walls, the experimentally observed tip morphologies may not represent the true three-dimensional behaviors of the arrays, especially for the cells with tip radii and primary arm spacings about the size of the melt thickness.

The question of whether the cells and dendrites grow with a steady-state shape is crucial for the development of a sound theoretical understanding of the arrayed growth during directional solidification. This research was aimed at answering this question. Succinonitrile-acetone alloy was selected for this study because of the ease of visualization, its well-characterized physical properties, and its metal-like

H. SONG, Research Associate, and S.N. TEWARI, Professor, are with the Chemical Engineering Department, Cleveland State University, Cleveland, $\mathrm{OH} 44115$.

Manuscript submitted July 25, 1995. solidification behavior. A range of growth speeds has been used to examine the behavior from near the breakdown of the planar liquid-solid interface to the fully developed dendritic arrayed growth. Time dependence of the tip morphology has been examined for the dendritic and cellular arrays. The observed variation (scatter) in the tip shape has been compared with that reported in the literature ${ }^{[2,15,16]}$ for growth in thin slab-shaped crucibles, without any convection in the melt.

\section{EXPERIMENTAL}

Details of the alloy preparation and directional solidification techniques have been presented earlier ${ }^{[17]}$ The directional solidification furnace, with the pyrex crucible $(0.7 \times$ 0.7-cm-square cross section), consisted of two axially aligned hollow $(1 \times 1-\mathrm{cm}$ cross section) cylindrical copper blocks (30-cm o.d.) separated by an air gap of 0.3 to 0.5 $\mathrm{cm}$ to provide the required thermal gradient $\left(G_{1}\right)$. Constant temperature water was made to flow at controlled flow rates through the internal channels machined within the copper blocks (for example, top $360 \mathrm{~K}$, bottom $275 \mathrm{~K}$, and air gap $=0.5 \mathrm{~cm}$, used in the present research, yielded a $G_{1}$ of 34.8 $\mathrm{K} \mathrm{cm}^{-1}$ ). Directional solidification was carried out by keeping the sample stationary and translating the furnace assembly at growth speeds from 0.1 to $6 \mu \mathrm{m} \mathrm{s}^{-1}$ with the help of a stepper motor. This avoided any convection due to the specimen translation and allowed a smooth translation of the thermal profile along the specimen length. The top and bottom copper blocks were suitably machined near the gap to provide a conical viewing path for examining the liquidsolid interface. The morphology of the liquid-solid interface could thus be observed parallel to the interface and also at an oblique angle (about $30 \mathrm{deg}$ from the vertical). An optical microscope coupled with a TV camera and videotape recording system was used to record the shape of the interface during growth. The specimens were remelted and solidified several times to obtain primary dendrites growing in the [100] direction, aligned nearly parallel to the growth direction. These specimens were then used for observing the cellular and dendritic array morphologies during several directional solidification experiments. One chromel-alumel thermocouple was incorporated in the sample to measure the thermal gradient in situ. The acetone content calculated from the dendrite tip measurement $\left(325.6 \mathrm{~K}\right.$, at $G_{1}=34.8$ 
$\mathrm{K} \mathrm{cm}^{-1}$ and growth speed $\left.=3 \mu \mathrm{m} \mathrm{s}^{-1}\right), 1.87 \mathrm{wt}$ pct, was in reasonable agreement with the amount of the acetone originally charged into the specimen, $1.9 \mathrm{wt}$ pct.

\section{RESULTS}

\section{A. Tip Morphology in the Presence of Convection}

Succinonitrile melt, because of its relatively larger Prandtl number, about 22.4 , is especially prone to natural convection due to a transverse thermal gradient, compared with, for example, metals. In addition, since the solute (acetone) is lighter than the solvent (succinonitrile), the solutal profiles, both within the intercellular/interdendritic melt and in the melt immediately ahead of the cell/dendrite tips, would be destabilizing and may cause thermosolutal convection. In the present study, we have not attempted to quantify and characterize convection, but extensive convection was observed during plane front directional solidification of succinonitrile-1.9 wt pct acetone alloy under similar growth conditions and experimental arrangements. ${ }^{[17]}$ It is, therefore, likely that the morphologies, described subsequently, are also influenced by convection.

Figure 1 shows the variation in the longitudinal microstructure as a function of growth speed for the succinonitrile$1.9 \mathrm{wt}$ pct acetone alloy grown at a thermal gradient of $34.8 \mathrm{~K} \mathrm{~cm}^{-1}$. These microstructures represent the morphologies 2 to 3 hours after the onset of breakdown of the planar liquid-solid interface and, therefore, are not likely to be affected by the initial transients, especially for the deep cells and dendrites. For this thermal gradient, the planar liquid-solid interface was observed to breakdown at a growth speed of $0.3 \mu \mathrm{m} \mathrm{s}^{-1}$. With increasing growth speed, the array morphology changed from cellular (without any side branches, $<0.5 \mu \mathrm{m} \mathrm{s}^{-1}$ ), as shown in Figure 1 (a), to unstable cells ("cactuslike" appearance, at $0.6 \mu \mathrm{m} \mathrm{s}^{-1}$ ), as shown in Figure 1 (b) (marked by arrows), to dendritic (well-developed side branches, $>0.7 \mu \mathrm{m} \mathrm{s}^{-1}$ ), as shown in Figure 1(c). A closer examination of the tip region in these microstructures shows that there is a large variation in the tip morphology of the cells within an array (Figure 1(a)). But, for the dendrite, there is very little variation in the tip morphology within the array (Figure 1 (c)). In Section B, we will examine the time dependence of the tip morphology for several single cells and dendrites.

Figure 2(a) shows the time-dependent variation in the tip shape of a typical cell growing at a speed of $0.4 \mu \mathrm{m} \mathrm{s}^{-1}$. The tips do not retain a constant steady-state shape. Instead, their shape fluctuates within a shape envelope. As a function of time, the tip which is initially convex toward the melt becomes flat. At this point, instability develops on the leading edge of the tip, which leads to a depression at the leading edge of the tip. However, unlike the "tip-splitting" phenomenon, which has been observed to lead to stable spacings, ${ }^{[13]}$ this instability is oscillatory in nature. The local cell spacing near the tip also fluctuates to accommodate this oscillation in the tip morphology. The preceding behavior was observed for most of the cells in the array. It is also important to note that the fluctuation in the curvature, from positive to negative, is generally localized in the middle of the leading edge of the cell tip.

At higher growth speeds, the leading edge of the tip was

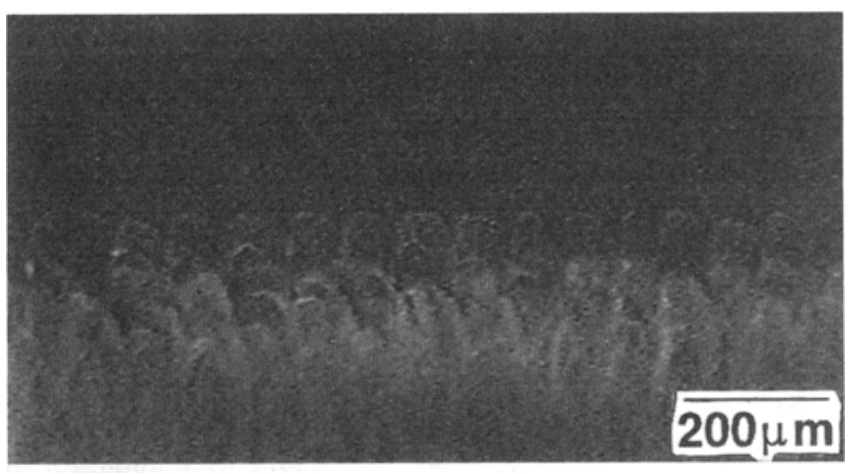

(a)

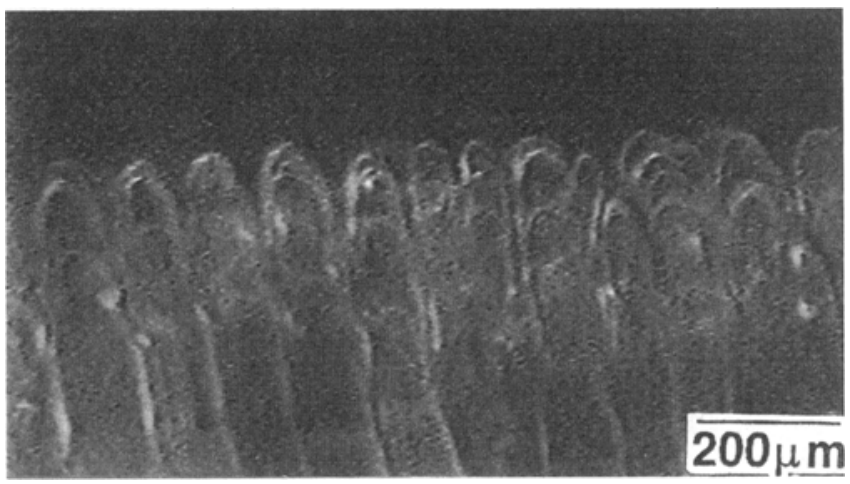

(b)

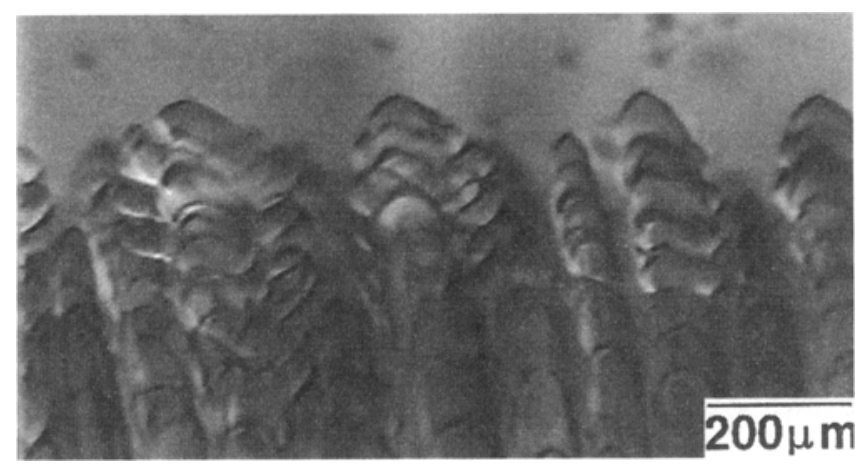

(c)

Fig. 1-Influence of growth speed on the cellular/dendritic array morphology during constrained growth of succinonitrile-1.9 wt pct acetone alloy at $34.8 \mathrm{~K} \mathrm{~cm}^{-1}$ (in the presence of natural convection): $(a)$ cells $\left(R=0.5 \mu \mathrm{m} \mathrm{s}^{-1}\right),(b)$ unstable cells $\left(R=0.6 \mu \mathrm{m} \mathrm{s}^{-1}\right)$, and $(c)$ dendrites $\left(R=0.8 \mu \mathrm{m} \mathrm{s}^{-1}\right)$.

observed to have more curvature (lower tip radius) and the location of the instability shifted from the middle of the leading edge toward the sides of the cell (Figure 2(b)) due to small deviation from the preferred growth direction. In this figure, the tip shapes, observed at different times for a cell growing at $0.6 \mu \mathrm{m} \mathrm{s}^{-1}$, have been superimposed to indicate the shape envelope in which the tip was observed to fluctuate. At this growth speed, the leading edge of the tip remains convex as a function of time. The instabilities tend to develop at either side of the tip but do not survive. At a still higher growth speed of $0.7 \mu \mathrm{m} \mathrm{s}^{-1}$, the curvature at the leading edge of the tip increases (the tip is still, however, not paraboloidal) and the instability develops further down the side of the primary cell, away from the tip (Figure 


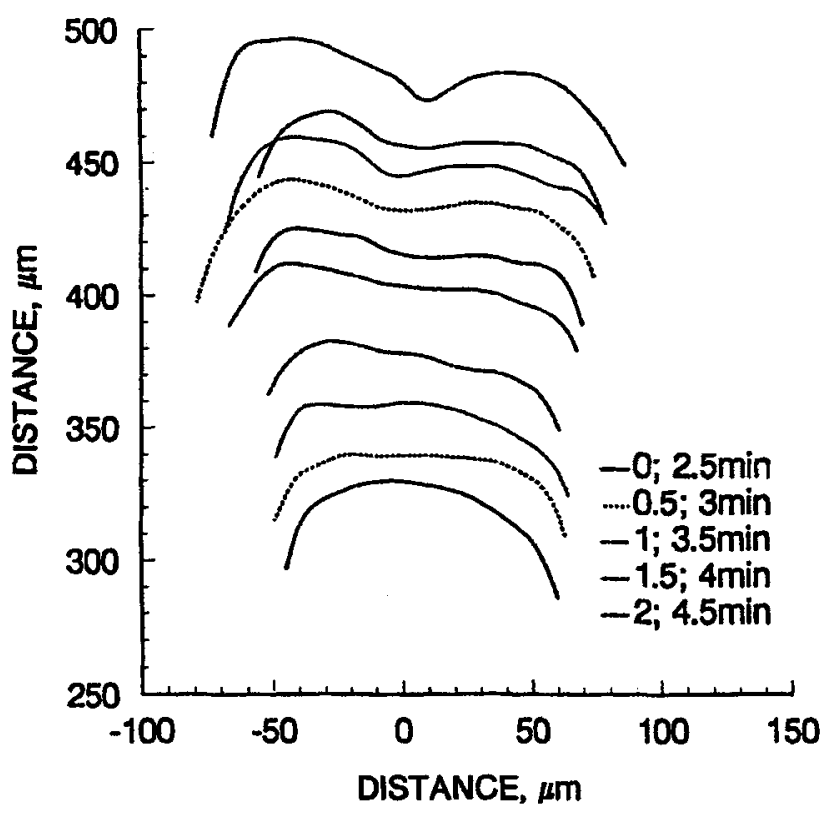

(a)

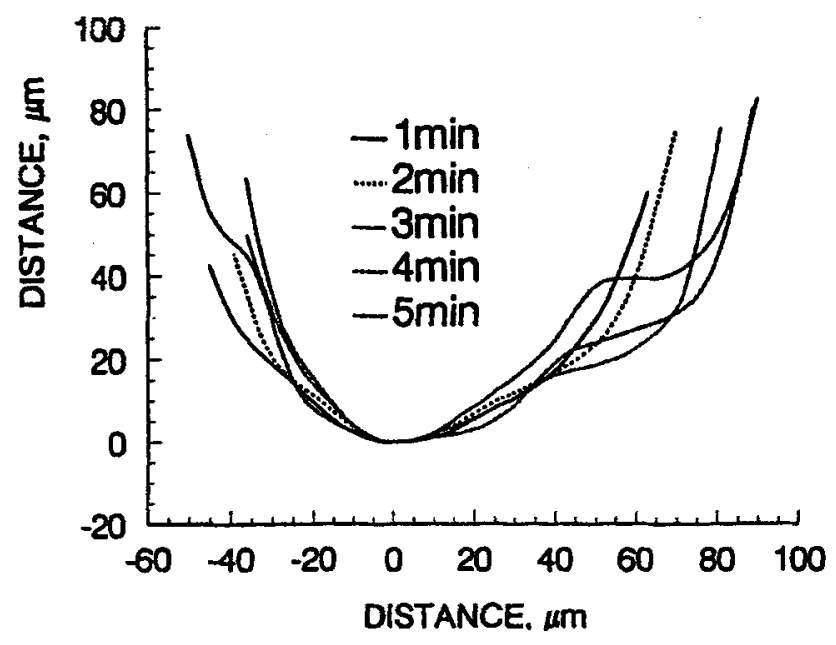

(c)

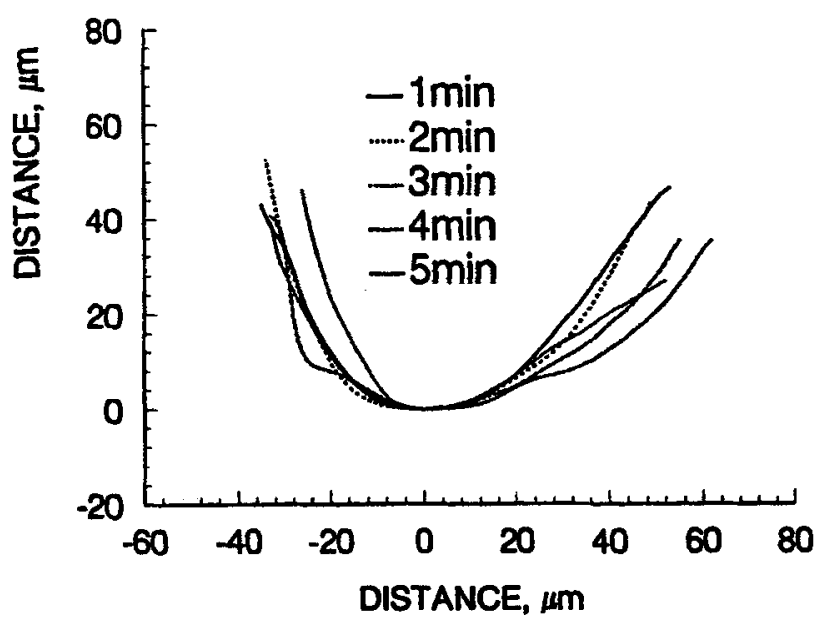

(b)

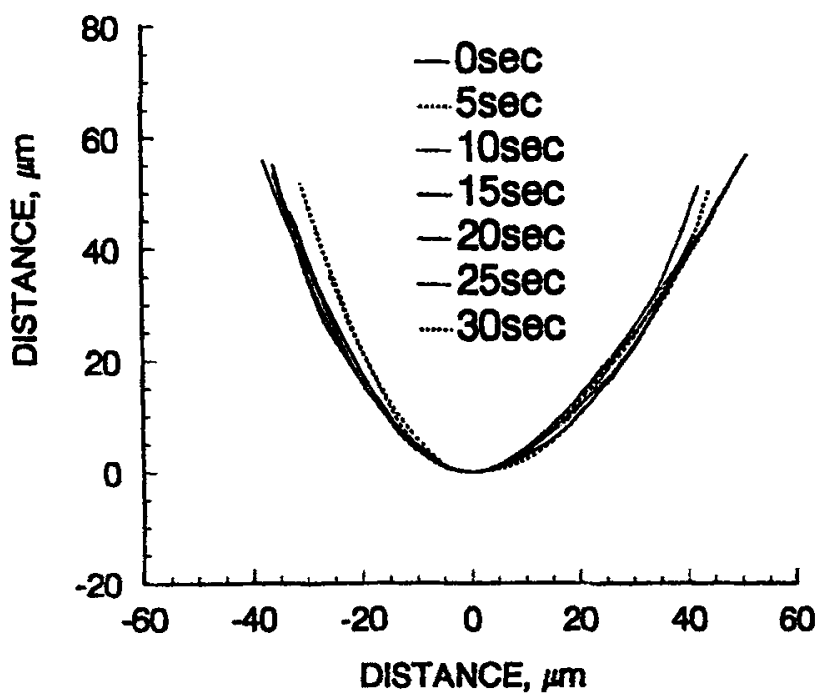

(d)

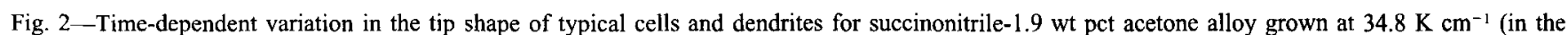

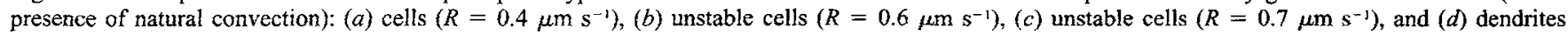
$\left(R=3.0 \mu \mathrm{m} \mathrm{s}^{-1}\right)$.

2(c)). However, unlike the stable cells growing at $0.4 \mu \mathrm{m}$ $\mathrm{s}^{-1}$, the instabilities now survive and lead to the unstable cells. The side instabilities in these cactuslike unstable cells (Figure 1(b)) were observed to grow at 12 to $16 \mathrm{deg}$ from the alloy growth direction. A mechanism for their formation will be presented later.

At growth speeds higher than $0.8 \mu \mathrm{m} \mathrm{s}^{-1}$, the formation of the side instability occurs further away from the tip (Figure 1(c)). The tip is now almost paraboloidal, and its shape is maintained in a much tighter shape envelope (Figure 2(d)) as compared to the morphologies observed at the lower growth speeds. (We will assume the tip to be paraboloidal if its shape follows a parabola, at least to a distance of about 5 tip radii, along its axis.) Unlike the previously described morphologies (cactuslike), the principal growth direction of the side instabilities is nearly $45 \mathrm{deg}$ from the alloy growth direction. These instabilities lead to the continual formation of the well-known side branches of the primary dendrites.

Figure 3 plots the time-dependent variation in the curvature along the tip surface as a function of the distance from the axis of the primary cell/dendrite. As the tip shape fluctuates, the maximum negative curvature is generally located in the middle of the leading edge of the tip (along the axis) for the stable cell morphologies (Figure 3(a)). It is shifted away from the central axis to either side for the unstable cactuslike cells (Figure 3(b)). The stable dendrites do not show any negative curvature at their tips (Figure $3(c))$. The maximum curvature for the dendrites is always at their tips along their growth axes; whereas, for the stable or unstable cells, the curvature along the tip surface is quite erratic. At any location on the tip, the curvature undergoes 


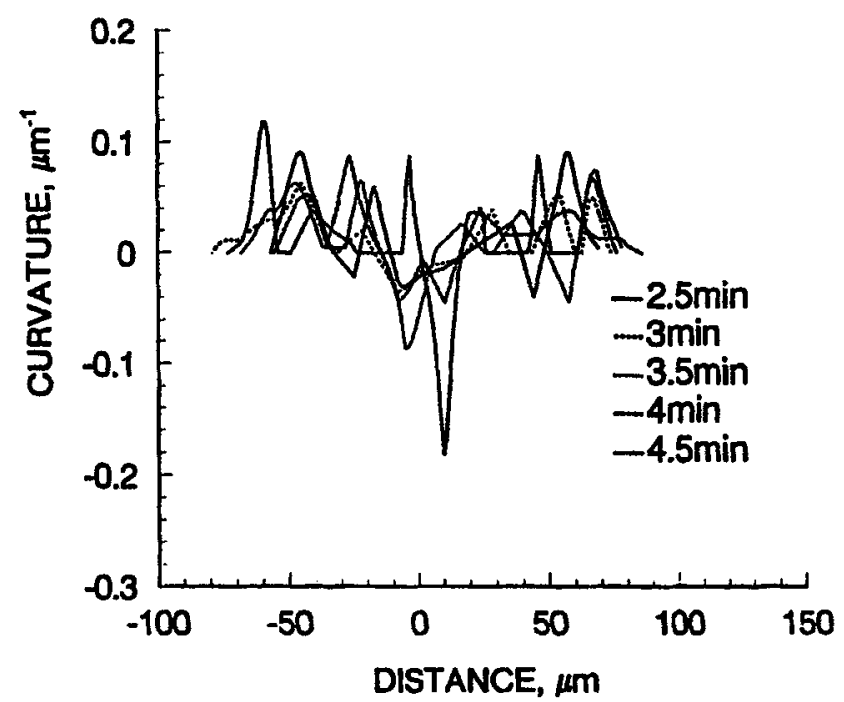

(a)

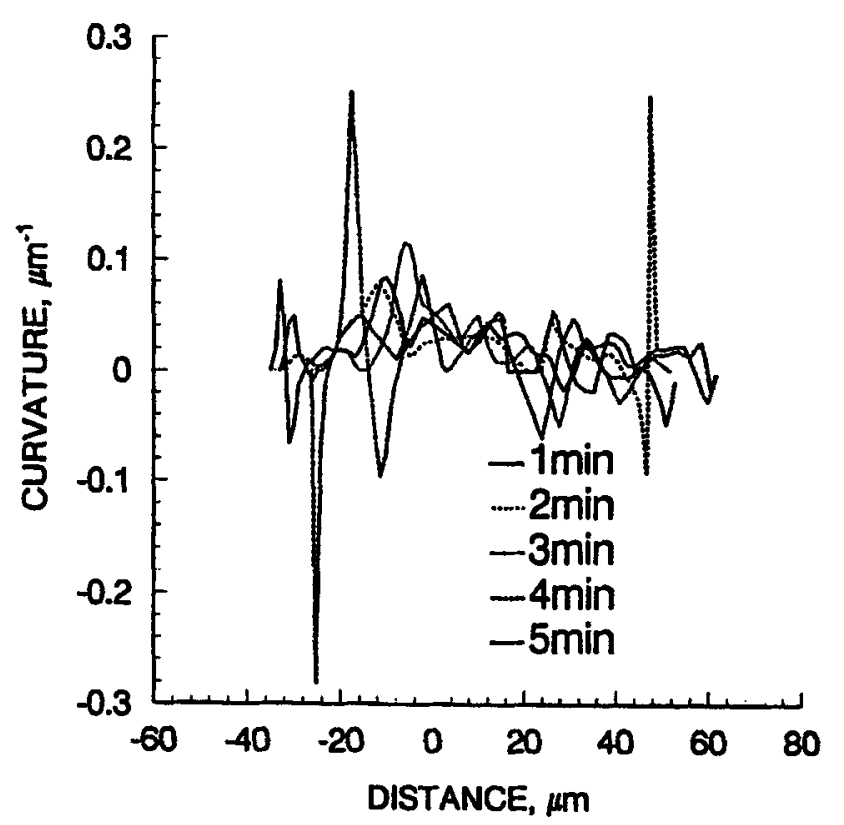

(b)

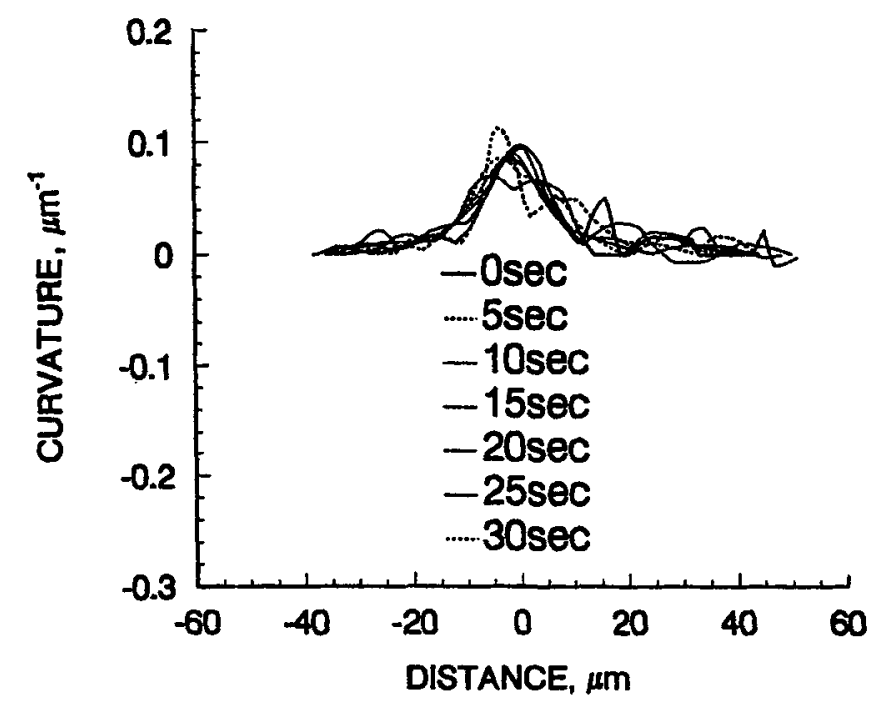

(c)

Fig. 3-Variation in the curvature along the tip surface of cells and dendrites as a function of time for succinonitrile-1.9 wt pct acetone alloy grown at $34.8 \mathrm{~K} \mathrm{~cm}^{-1}$ (in the presence of natural convection): (a) cells $\left(R=0.4 \mu \mathrm{m} \mathrm{s}^{-1}\right),(b)$ unstable cells $\left(R=0.6 \mu \mathrm{m} \mathrm{s}^{-1}\right)$, and $(c)$ dendrites $(R=3.0 \mu \mathrm{m}$ $\left.\mathrm{s}^{-1}\right)$.

considerable variation as the morphology fluctuates within a relatively large shape envelope.

\section{B. Tip Morphology in the Absence of Convection}

Figure 4 shows typical cell and dendrite tip morphologies, obtained from the literature, ${ }^{[16]}$ for transparent organic alloy (polyvinyl alcohol-0.076 wt pct ethanol) grown in thin slab-shaped ampoules, where convection was eliminated because of the very narrow melt column. In this figure, the tip morphologies for 8 to 10 of the neighboring cells or dendrites, on the longitudinal sections, have been superimposed to examine the extent of the scatter in their tip shapes. The dendrite tips show a very good match with each other (Figure 4(a)), but the cell tips show a large variation (Figure 4(b)). Similar to the previously described behavior of succinonitrile-acetone, grown in the presence of convec- tion (Figure 3), the maximum curvature for the dendrites is located at the leading edge of the tips (Figure 5(a)) and, for the cells, at varying locations on the tip surface (Figure 5(b)).

\section{Growth Speed Dependence of Tip Radii}

Figure 6 shows the extent of the experimentally observed scatter in the tip radii for cellular and dendritic morphologies as a function of growth speed. The tip radii were obtained by superimposing the best fitting parabola at the cell/dendrite tip. The tip radius measurements are more accurate for the dendrites, because they have a paraboloidal shape, at least to a length of 5 tip radii along their axis. The cells do not have a paraboloidal shape. However, their tip shape was also assumed to be paraboloidal in obtaining the tip radii. The filled symbols correspond to the dendrites 


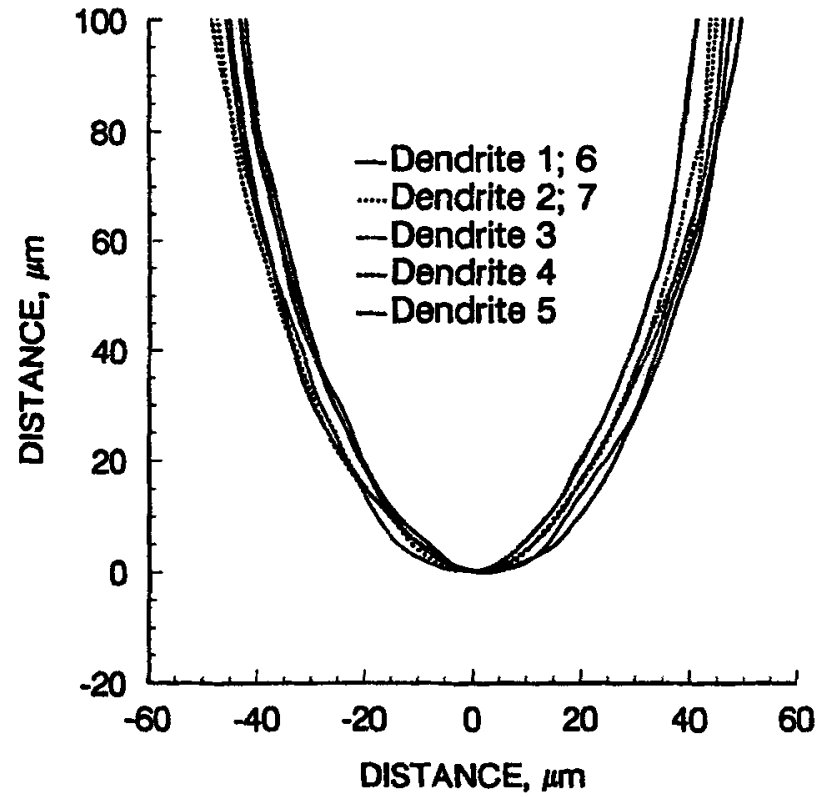

(a)

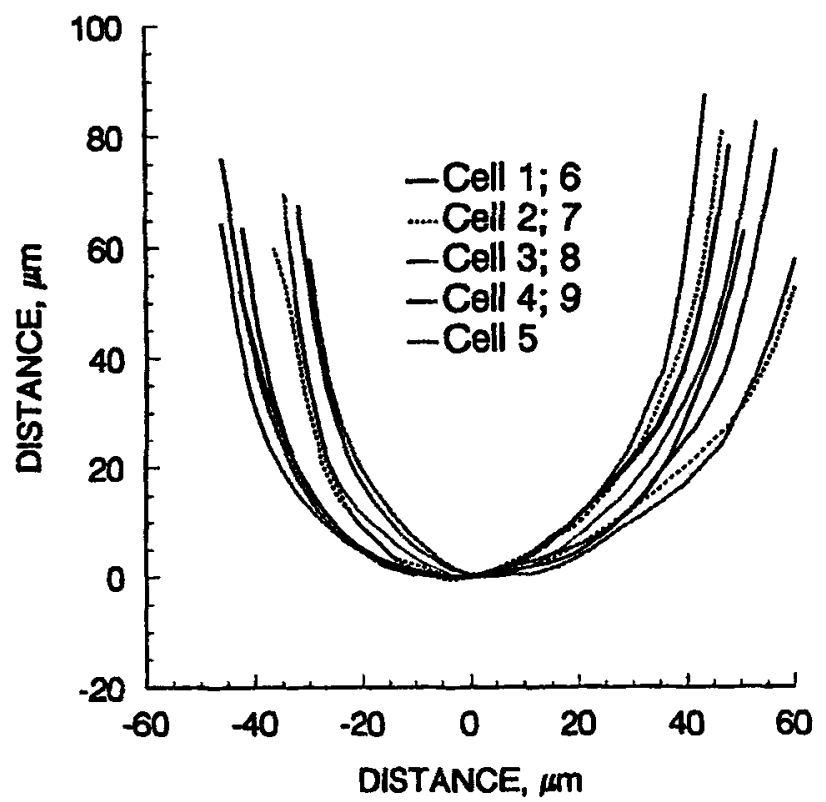

(b)

Fig. 4-Typical variation in the cell/dendrite tip morphology in polyvinyl alcohol- $0.076 \mathrm{wt}$ pct ethanol directionally solidified in the absence of natural convection $\left(G_{1}=29.8 \mathrm{~K} \mathrm{~cm}^{-1}\right):{ }^{[16]}(a)$ dendrites $\left(R=7 \mu \mathrm{m} \mathrm{s}^{-1}\right)$ and $(b)$ cells $\left(R=0.5 \mu \mathrm{m} \mathrm{s}^{-1}\right)$.

and the open symbols to the cells. Figure 6(a) plots the tip radii in succinonitrile-1.9 wt pct acetone alloy (grown in the presence of natural convection). There is considerable scatter in the tip radius values, the extent of scatter increasing with the decreasing growth speed. The scatter is much larger for the cellular morphologies than for the dendrites. Can we attribute this scatter to the natural convection in the melt? An examination of the literature on tip radii, obtained from the specimens grown in convection-free thin slab-shaped crucibles, ${ }^{[2,25]}$ indicates similar behavior. As shown in Figure 6(b), for succinonitrile-5.5 mol pct acetone $^{[2]}$ (circular symbols) and succinonitrile-1.65 wt pct salol ${ }^{[15]}$ (triangular symbols), the scatter in the tip radii is minimal for dendrites but is quite large for the cells, even

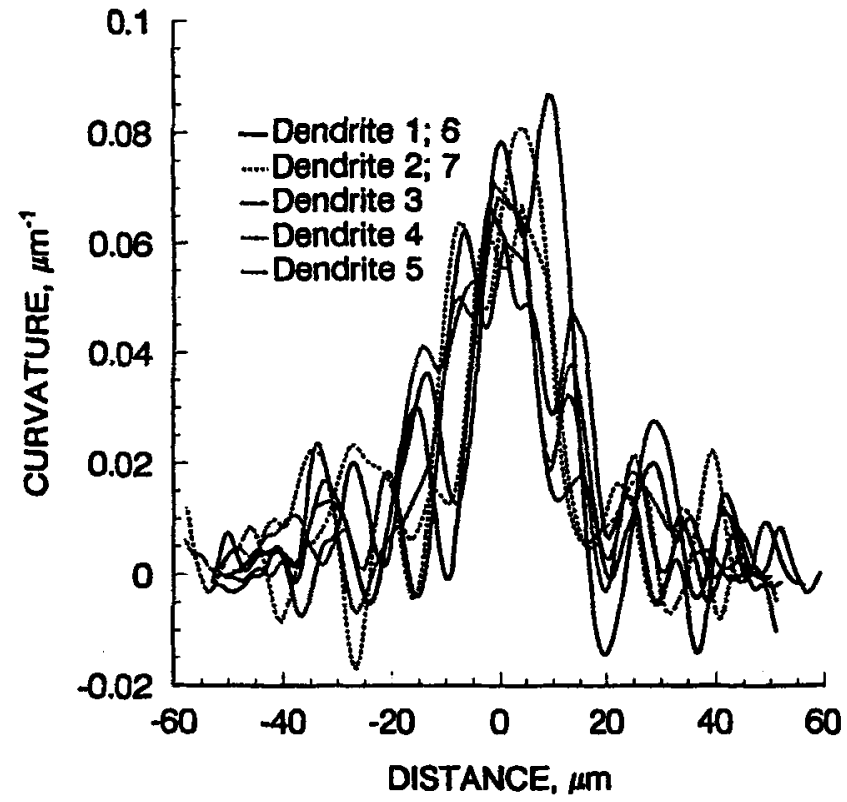

(a)

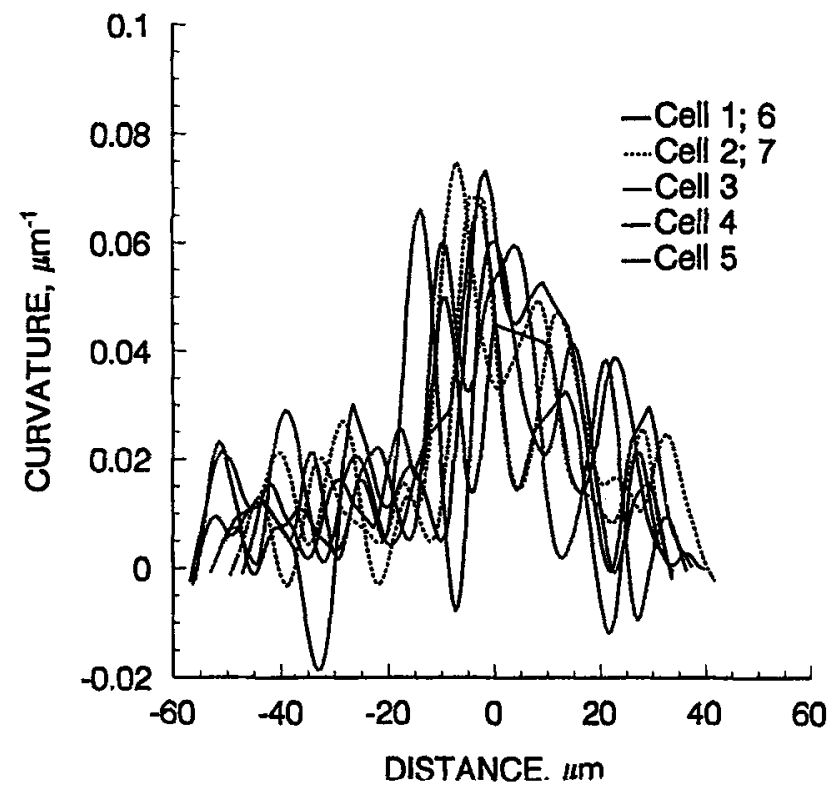

(b)

Fig. 5-Variation in the curvature along the tip surface of cells and dendrites for polyvinyl alcohol-0.076 wt pct ethanol directionally solidified in the absence of natural convection $\left(G_{\mathrm{I}}=29.8 \mathrm{~K} \mathrm{~cm}^{-1}\right)^{1168}(a)$ dendrites $\left(R=7 \mu \mathrm{m} \mathrm{s}^{-1}\right)$ and $(b)$ cells $\left(R=0.5 \mu \mathrm{m} \mathrm{s}^{-1}\right)$.

in the absence of convection. It should also be mentioned here that these figures do not correspond to the shallow cells formed in the vicinity of the breakdown of a planar liquid-solid interface, where time-dependent cell morphologies have been reported by Lee et al., ${ }^{[18]}$ but these are deep cells growing under conditions of much larger instability. The dotted lines in Figures 6(a) and (b) correspond to the theoretically predicted tip radii for the succinonitrile-acetone alloys and will be discussed later.

\section{Cell to Dendrite Transition and Side Branching}

Figures 7 and 8 show the evolution of the side instabilities for the cactuslike unstable cells and dendrites in the 


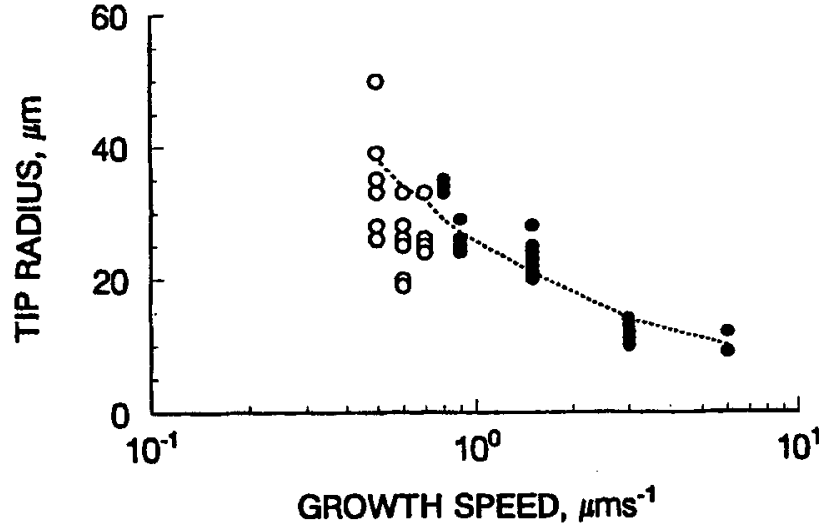

(a)

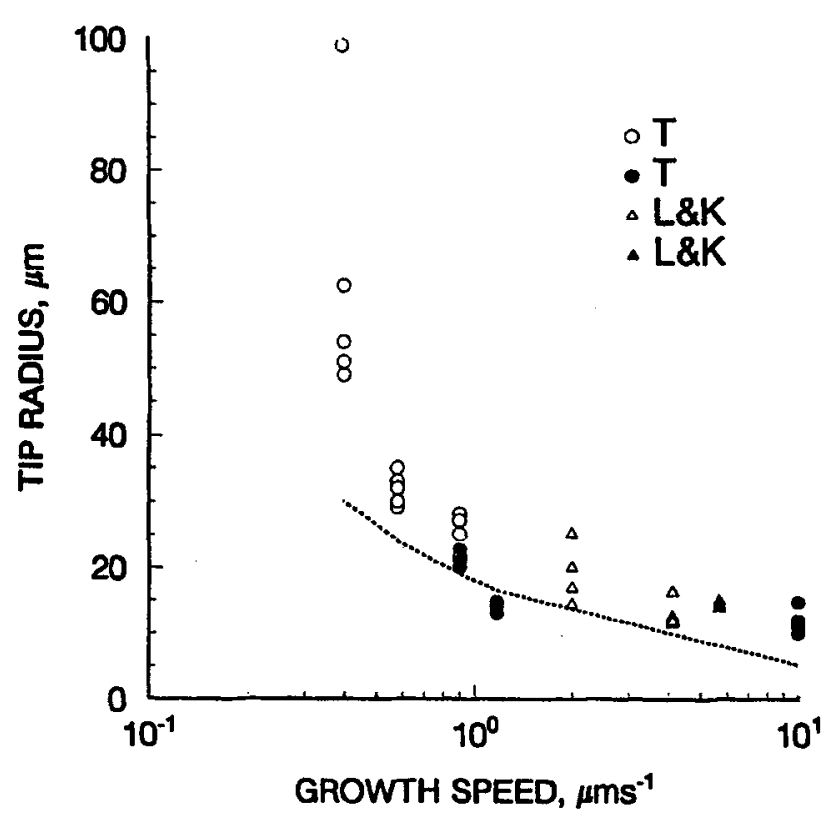

(b)

Fig. 6-Growth speed dependence of tip radii in transparent organic analogue alloys. Filled symbols are for dendrites, and open symbols are for cells. The dotted lines are the calculated tip radii for the stability parameter $\left(\sigma^{*}\right)$ equal to 0.025 . (a) Succinonitrile-1.9 wt pct acetone, grown in the presence of natural convection. (b) Succinonitrile-5.5 mol pct acetone ${ }^{[2]}$ (circular symbols) and succinonitrile-1.65 wt pct salol ${ }^{[15]}$ (triangular symbols), grown without natural convection.

immediate vicinity of the cell to dendrite transition. The insets in Figures 7(a) and 8(a), respectively, represent the variation in the shape of a typical unstable cell, growing at $0.6 \mu \mathrm{m} \mathrm{s}^{-1}$, and a dendrite, growing at $0.8 \mu \mathrm{m} \mathrm{s}^{-1}$. The data points indicate the location (distance along the alloy growth direction) of the tip and the various side instabilities as a function of time. The corresponding side instabilities have been marked as the 1 st, 2nd, 3rd, or 4th branch in these figures.

Figure 7 (a) shows the interaction between the existing side instability (1st branch) with the onset and growth of the subsequent instability at the tip (2nd branch), which is responsible for the formation of the unstable cactuslike cells. The first view at the bottom shows the onset of the 2nd instability on the side of the cell tip. Two lobes begin to form at the cell tip, the one on the right side growing and ultimately leading to the formation of the 2 nd branch. The one on the left side, however, grows at a speed faster

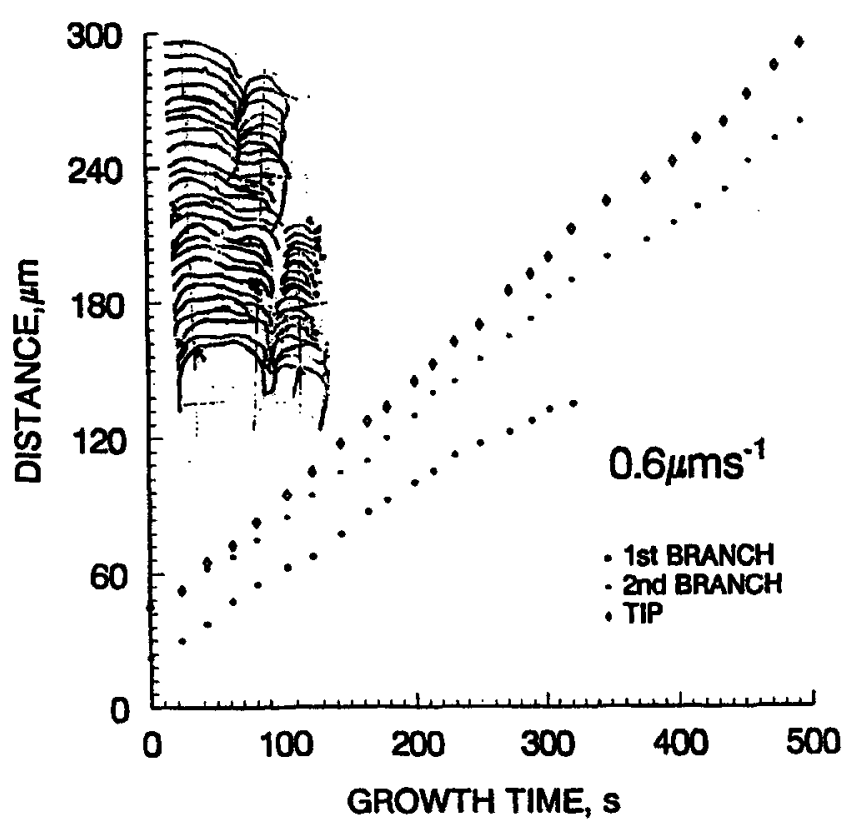

(a)

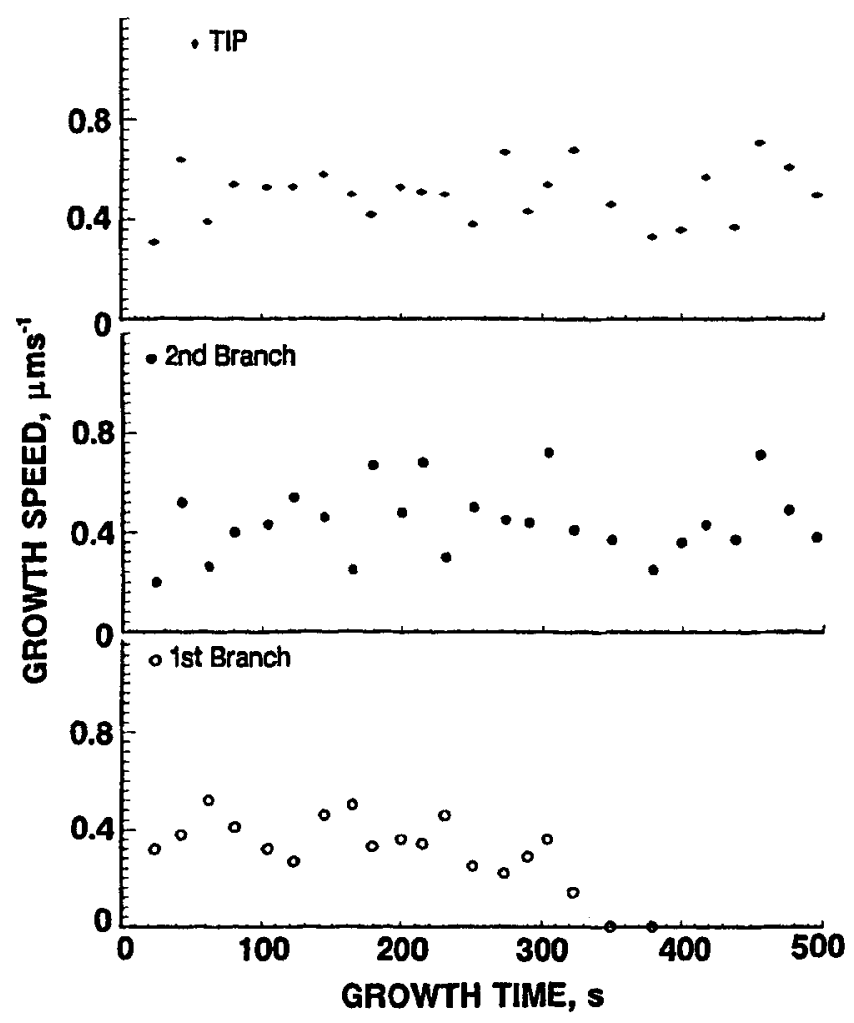

(b)

Fig. 7-Side branch evolution during directional solidification of succinonitrile-1.9 wt pct acetone with an unstable cell morphology $\left(G_{1}=\right.$ $34.8 \mathrm{~K} \mathrm{~cm}^{-1}$ and $R=0.6 \mu \mathrm{m} \mathrm{s}^{-1}$ ). The inset shows the variation in the tip morphology as a function of time. (a) Location (parallel to the growth direction) of the tip and side branches as a function of time. $(b)$ Growth speed (parallel to the specimen growth direction) of the tip and side branches as a function of time.

than the one on the right; i.e., the distance between the tips of the cell and the 2 nd branch continuously increases, the tip growing faster than the side branch. Also, the solute rejected by the growth of the 2 nd branch suppresses the growth of the pre-existing 1 st branch. Finally, the 1st 


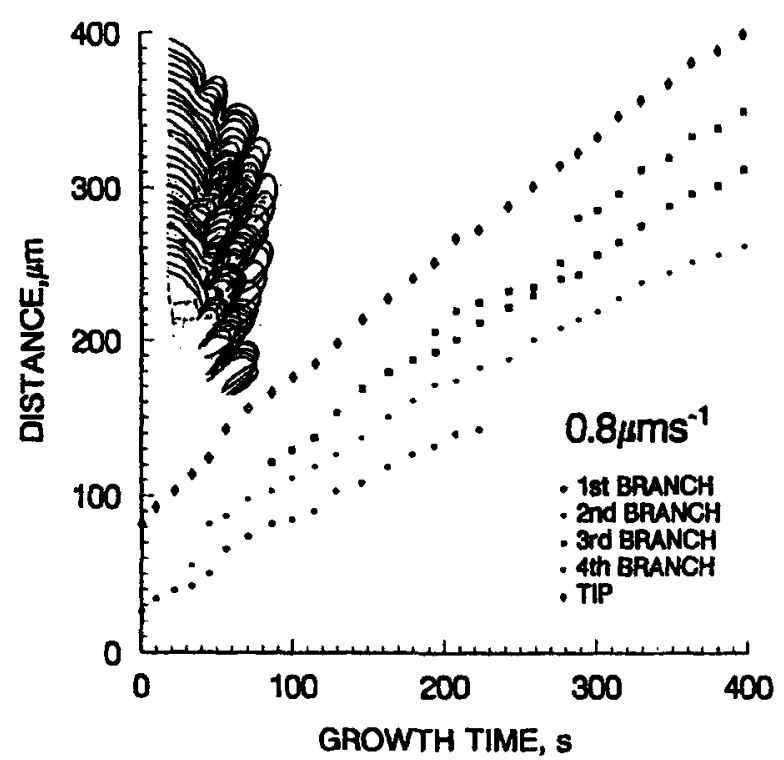

(a)

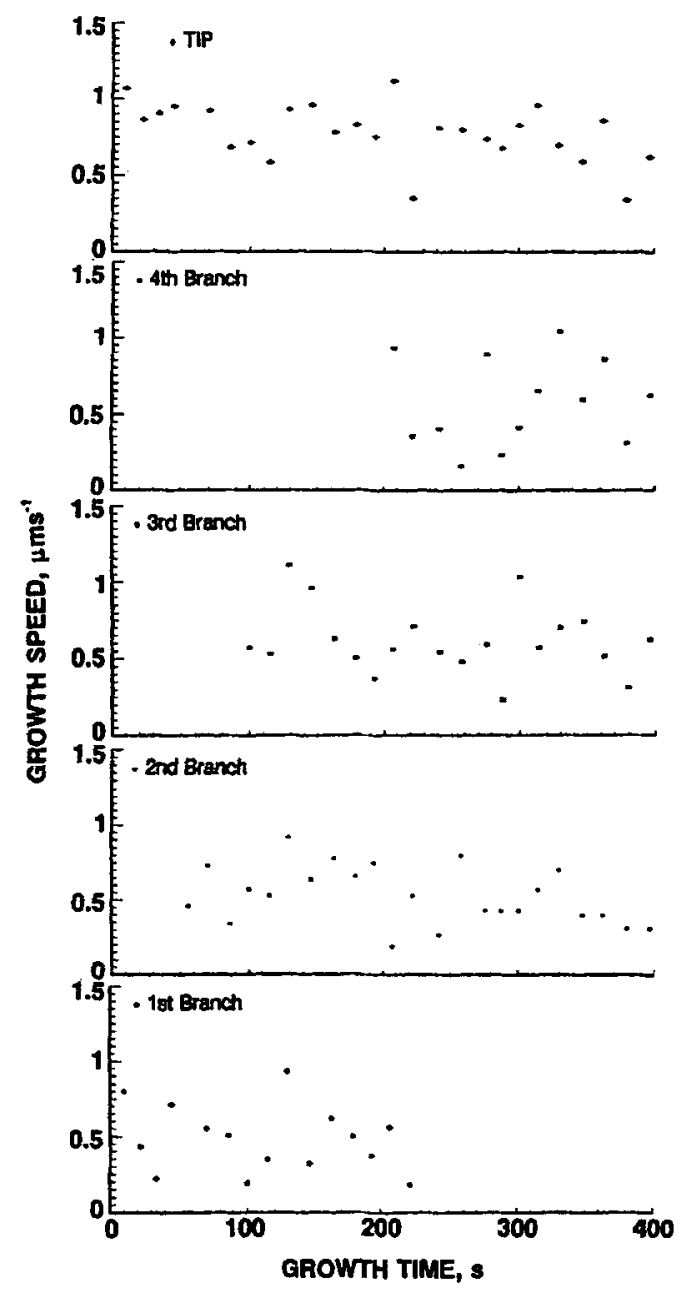

(b)

Fig. 8--Side branch evolution during directional solidification of succinonitrile-1.9 wt pct acetone with a dendritic morphology $\left(G_{1}=34.8\right.$ $\mathrm{K} \mathrm{cm}^{-1}$ and $R=0.8 \mu \mathrm{m} \mathrm{s}^{-1}$ ). The inset shows the variation in the tip morphology as a function of time. (a) Location (parallel to the growth direction) of the tip and side branches as a function of time. $(b)$ Growth speed (parallel to the specimen growth direction) of the tip and side branches as a function of time. branch stops growing, as indicated in Figure 7(b), which plots the growth speeds of the tip and the two side branches, parallel to the primary dendrite, as a function of time. As the time progresses, the radius of the cell tip again increases, leading to the development and growth of another instability on its side. Repetition of this cycle leads to the formation of the cactuslike appearance for the array. It is interesting to note that the distance between the cell tip and the tip of the side branch at its onset is nearly zero for the unstable cell morphology.

Unlike the unstable cactuslike cells, where the instabilities developed near the tips, the side branch formation for the dendrites occurs away from the tip (Figure 8(a)) at a distance of about $40 \mu \mathrm{m}$. This distance is nearly the same for all the side branches at their onset. Similar to the unstable cell morphology, the onset of another side branch appears to slow the growth speed of the previous branch (notice the continuously increasing distance between the dendrite tip and the tip of the 1 st branch). However, the onset and growth of a side branch near the tip do not completely suppress the growth of the pre-existing side branch. Notice that the growth of the 1st branch continues even after the subsequent formation of four more side branches.

The time dependence of the growth speeds (parallel to the alloy growth direction) of the dendrite tip and the four side instabilities, in the vicinity of the cell to dendrite transition, is shown in Figure 8(b). There is considerable noise in the data. However, the tip appears to have oscillatory behavior, its speed fluctuating above and below the nominal growth speed of $0.8 \mu \mathrm{m} \mathrm{s}^{-1}$ as a function of time, with a wavelength of about 100 seconds. The minimum step provided by the stepper motor, used for translating the furnace, is $0.1 \mu \mathrm{m}$, which also ensures a constancy of the translation velocity to within $0.05 \mu \mathrm{m} \mathrm{s}^{-1}$. Therefore, these periodic fluctuations (100 seconds) cannot be due to fluctuations in the translation velocity.

The question arises whether this behavior is due to convection in the melt or to the side branching activity (every $40 \mu \mathrm{m}$ or 50 seconds, a side branch forms near the tip, Figure 8(a)). A closer examination of Figure 7(b), corresponding to the unstable cell morphology, also shows fluctuations in the tip speed. However, these fluctuations appear to be more random, and not with a constant wavelength. Unless the convective flows themselves changed from time periodic to random with the minor change in the growth speed (from 0.8 to $0.6 \mu \mathrm{m} \mathrm{s}^{-1}$ ), the fluctuations in the growth speed of the dendrite tip can be assumed to be associated with the side-branching instability. Similar directional solidification experiments, carried out in the low gravity environment of space, could help answer the preceding question.

\section{DISCUSSION}

In the absence of convection, the tip morphology (tip radius $=r_{t}$ ) is expected to be determined by a balance among the three competing factors at the tip: stabilizing positive effective thermal gradient $(G)$, destabilizing solutal gradient $\left(G_{c}\right)$, and stabilizing capillarity (liquid-solid surface energy and its anisotropy). The morphological stability assumption, $\sigma^{*}=\Gamma /\left(m_{1} G_{c}-G\right) r_{t}^{2}$ (where $\Gamma$ is the capillary constant, the ratio of the liquid-solid surface energy to melt- 


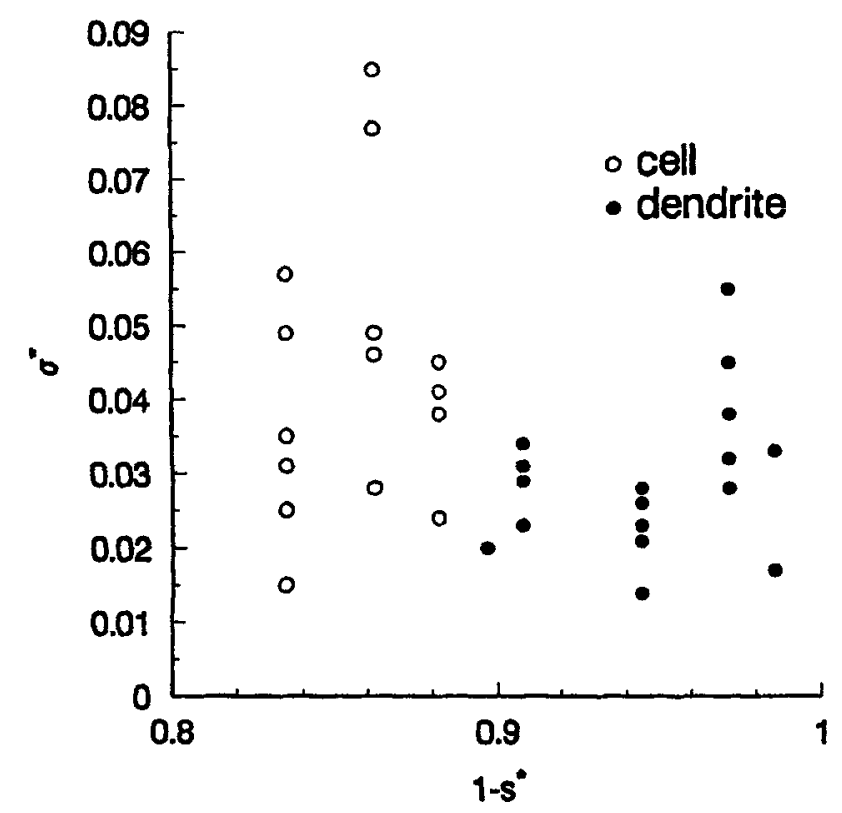

(a)

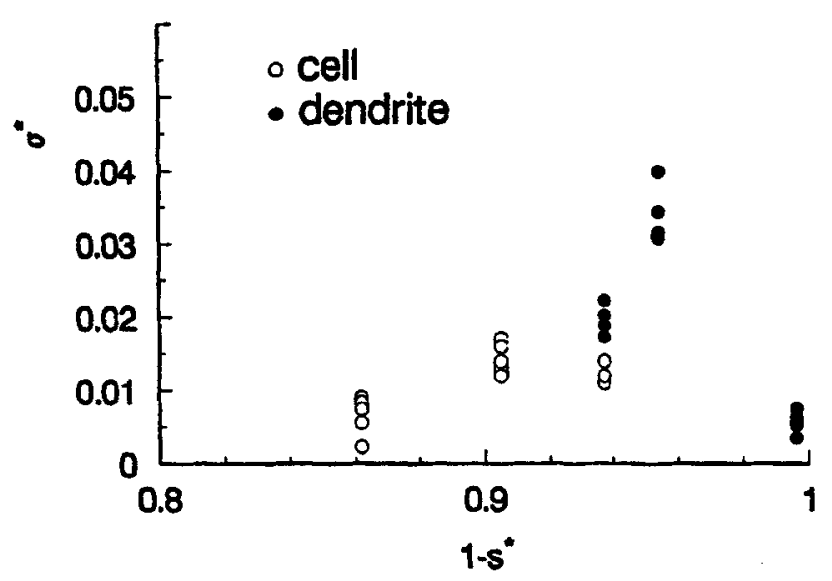

(b)

Fig. 9-Dependence of the experimentally observed stability parameter $\sigma^{*}$ on $\left(1-S^{*}\right)$. (a) Succinonitrile-1.9 wt pct acetone, grown in the presence of natural convection. (b) Succinonitrile-5.5 mol pct acetone, grown without natural convection. [15]

ing entropy), even though physically inaccurate,$^{[14]}$ has been successfully used to predict the dendrite tip radius. The stability constant, $\sigma^{*}$, has been observed to be about $0.025^{[19]}$ for dendrites. However, a preliminary examination of the literature reported data showed that cells do not have the same $\sigma^{*}$ as the dendrites. ${ }^{[20]}$ Is it because the dendrite tips are always paraboloidal in shape, whereas the cells have paraboloidal, elliptical, and spherical tip morphologies (excluding the shallow cells formed during the initial transient just after the breakdown of the planar liquid-solid interface)? The concentration gradient ahead of the cellular/dendritic tips, $G_{c}$, can be calculated by combining the gradient from behind the tip (due to the interdendritic solutal profile) and that for an isolated parabola or sphere. ${ }^{[6,8,21]}$ Using this approach, the stability constant, $\sigma^{*}$, can be expressed as follows:

(a) for a spherical tip,

$$
\begin{aligned}
& \sigma^{*}=\left\{\Gamma D_{1} / m_{1} C_{0}(k-1)\right\}\left\{R r_{1}^{2}\left(1-S^{*}\right)\right\}^{-1} \\
&\{1-2 P(1-k)\}
\end{aligned}
$$

(b) for a paraboloidal tip,

$$
\begin{aligned}
& \sigma^{*}=\left\{\Gamma D_{1} / m_{1} C_{0}(k-1)\right\}\left\{R r_{t}^{2}\right. \\
&\left.\left(1-S^{*}\right)\right\}^{-1}\left\{1-\mathrm{I}_{\mathrm{v}}(P)(1-k)\right\}
\end{aligned}
$$

where $P=\operatorname{Rr} / D_{1}, I_{v}(P)=$ Ivantsov function, ${ }^{[21]} S^{*}=$ $D_{1} G k / R m_{1} C_{0}(k-1), D_{1}=$ diffusion coefficient of solute in the melt, $k=$ partition coefficient, $R=$ growth speed, and $m_{1}=$ liquidus slope. The $\left(1-S^{*}\right)$ term varies from zero to one, its value being zero for a planar liquid-solid interface, slightly higher for cells, and closer to one for dendrites. The difference between the spherical and paraboloidal shapes is manifested in the last term in the preceding two relations. This term can be neglected if $P$ and $I_{v}(P)$ are much less than one, as is the case with the growth conditions presented in Figure 6 . The tip radii values calculated from the previous relationships, assuming $\sigma^{*}$ to be 0.025, are plotted as dotted lines in Figures 6(a) and (b) for the succinonitrile-acetone alloys. It is quite surprising that the observed tip radii are generally in good agreement with the predicted values in spite of the extensive convection present during their growth (Figure 6(a)). This is especially true for the dendrites. For the cells, the tip radii are less than the predicted values in the presence of convection (Figure 6(a)) and are larger than the predicted values in the absence of convection (Figure 6(b)), suggesting that convection reduces the tip radii.

Figure 9 plots the $\sigma^{*}$ values from Eq. [1], based on the experimentally observed $R$ and $r_{t}$, as a function of $\left(1-S^{*}\right)$ for the succinonitrile-acetone alloys, grown in the presence (Figure 9(a)) and absence (Figure 9(b)) of convection. In general, the scatter in $\sigma^{*}$ is larger for growth in the presence of convection than in its absence. Also, the $\sigma^{*}$ values are generally greater than 0.025 in the presence of convection (Figure 9(a)) and tend to be less than 0.025 in its absence (Figure 9(b), except for the one set of data corresponding to $\left.\left(1-S^{*}\right)=0.955\right)$. In other words, convection not only increases the tip radius fluctuations, but also tends to decrease the tip radii, especially for the cellular morphology.

The cell to dendrite transition for succinonitrile-acetone alloys occurs at $\left(1-S^{*}\right)=0.89$ in the presence of convection (Figure $9(\mathrm{a}))$ and at $\left(1-S^{*}\right)=0.94$ in its absence (Figure 9(b)). For succinonitrile-salol also, the transition, in the absence of convection, occurs at $\left(1-S^{*}\right)=0.95$ (Figure 6(b)). These data suggest that a larger gradient of constitutional supercooling is required for the side-branch instability to occur under convection free growth as compared with that in the presence of convection. This is contrary to the earlier observed ${ }^{[17]}$ stabilizing influence of convection on the planar to cellular breakdown in $\mathrm{Pb}-10 \mathrm{wt}$ pct $\mathrm{Sn}$ and succinonitrile-1.9 wt pct acetone, where convection was observed to provide stability against breakdown. The growth speed required for the breakdown of a planar liquid-solid interface was about $0.3 \mu \mathrm{m} \mathrm{s}^{-1}$ in the presence of natural convection, as compared with $0.086 \mu \mathrm{m}$ $\mathrm{s}^{-1}$ expected from the linear stability analysis of Mullins and Sekerka ${ }^{[22]}$ for a purely diffusive mass transport. This observation was in agreement with the theoretical analysis of Favier and Rouzaud, ${ }^{[23]}$ suggesting that convection decreases the concentration gradient ahead of any perturbation 
at a planar liquid-solid interface by more efficient lateral (sideways) distribution of solutes. The interface, therefore, breaks down at growth speeds higher than that expected for purely diffusive transport. Apparently, a similar mechanism does not operate along the cell surface in the intercellular region near the cell tips; instead, the convection leads to solute accumulation and promotes side-branch formation.

The previously discussed observations raise some very interesting questions. Are the cell tips inherently more susceptible to the experimental "noise" than the dendrites? Does the large driving force for the dendritic growth (extent of constitutional supercooling ahead of the tips) or crystallographic anisotropy overpower the experimental noise and help maintain a steady-state shape, as compared to the cells? What is the source of this noise: convection related temperature and composition fluctuations at the tips or the natural competition among the neighboring cells/dendrites? There is clearly a need to answer the basic question raised by Langer, ${ }^{[24]}$ "How are the cellular patterns selected and controlled or is there a sharp selection mechanism?" The data generated by terrestrial directional solidification experiments on transparent alloys are, however, not adequate. Growth morphologies observed in the large ampoules are affected by convection and those in the thin slabs are affected by the wall effects. This is especially true for the cellular array morphology. Low gravity directional solidification experiments on well-characterized transparent binary alloys would help answer some of these questions.

\section{CONCLUSIONS}

The time dependence of cell/dendrite tip morphology has been examined during directional solidification of succinonitrile- $1.9 \mathrm{wt}$ pct acetone in $0.7 \times 0.7-\mathrm{cm}$-square cross section pyrex ampoules in order to eliminate the influence of wall effects. The observed morphologies have been compared with those reported for the specimens grown in narrow (about 200- $\mu \mathrm{m}$ wide) ampoules to eliminate convection in the melt. The following conclusions can be drawn from this study.

1. The dendrite tips do not maintain a steady-state shape during growth. Instead, they fluctuate within a shape envelope. The fluctuations appear to correspond to the formation of side branches.

2. The extent of fluctuation is larger for the cells, as compared with the dendrites. It increases with decreasing gradient of constitutional supercooling.

3. The scatter in the tip radii due to the shape fluctuation is increased in the presence of convection, especially for the cells. The convection also decreases the gradient of constitutional supercooling required for the onset of cell to dendrite transition.

4. Low gravity directional solidification experiments on well-characterized transparent binary alloys are required to determine whether a sharp selection mechanism exists for cellular tip morphologies.

\section{ACKNOWLEDGMENTS}

This research was supported by the Microgravity Science and Applications Division, NASA, at the NASA-Lewis Research Center (Cleveland, $\mathrm{OH}$ ). The authors are grateful to Professor R. Trivedi for his review and comments. Appreciation is expressed to Dr. A.M. Chopra for her help during this research and to Thomas K. Glasgow for his continued encouragement and support.

\section{REFERENCES}

1. H. Esaka and W. Kurz: J. Cryst. Growth, 1985, vol. 72, pp. 578-84.

2. R. Trivedi: Metall. Trans. A, 1984, vol. 15A, pp. 977-82.

3. R. Trivedi and K. Somboonsuk: Acta Metall., 1985, vol. 33, pp. 1061-68.

4. R. Trivedi and J.T. Mason: Metall. Trans. A, 1991, vol. 22A, pp. 23549.

5. D. Venugopalan and J.S. Kirkaldy: Acta Metall., 1984, vol. 32, pp. 893-906.

6. M.H. Burden and J.D. Hunt: J. Cryst. Growth, 1974, vol. 22, pp. 99-116.

7. R. Trivedi: J. Cryst. Growth, 1980, vol. 49, pp. 219-32.

8. V. Laxmanan: J. Cryst. Growth, 1986, vol. 83, pp. 573-90.

9. J.S. Kirkaldy: Scripta Metall., 1980, vol. 14, p. 739.

10. A. Karma and P. Pelce: Phys. Rev. A, 1989, vol. 39, pp. 4162-69.

11. L.H. Unger, M.J. Bennett, and R.A. Brown: Phys. Rev. B, 1985, vol. 31, pp. 5923-40.

12. J.D. Hunt and D.G. McCartney: Acta Metall., 1987, vol. 35, pp. 89 99

13. S.Z. Lu and J.D. Hunt: J. Cryst. Growth, 1992, vol. 123, pp. 17-34.

14. J.A. Warren and J.S. Langer: Phys. Rev. A, 1990, vol. 42, pp. 3518 25.

15. L.X. Liu and J.S. Kirkaldy: Scripta Metall. Mater, 1993, vol. 28, pp. 1029-34.

16. M.A. Eshelman, V. Seetharaman, and R. Trivedi: Acta Metall., 1988, vol. 36, pp. 1165-74.

17. S.N. Tewari and M.A. Chopra: J. Cryst. Growth, 1992, vol. 18, pp. 183-92.

18. J.T.C. Lee, K. Tsiveriotis, and R.A. Brown: J. Cryst. Growth, 1992, vol. 121 , pp. 536-42.

19. W. Kurz and R. Trivedi: Acta Metall, 1990, vol. 38, pp. 1-17.

20. S.N. Tewari and R. Trivedi: Microgravity Sci. Technol., 1991, vol. 4, pp. $240-44$.

21. J. Lipton, M.E. Glicksman, and W. Kurtz: Mater. Scì. Eng., 1984 , vol. 65 , pp. 57-63.

22. W.W. Mullins and R.F. Sekerka: J. Appl. Phys., 1963, vol. 34, pp. 444-51.

23. J.J. Favier and A. Rouzaud: J. Cryst. Growth, 1987, vol. 64, pp. 36779.

24. J.S. Langer: Metall. Trans. A, 1984, vol. 15A, pp. 961-66. 